\title{
Mental health is the most important factor influencing quality of life in elderly left behind when families migrate out of rural China ${ }^{1}$
}

\author{
Jian-fei Xie ${ }^{2}$ \\ Si-qing Ding ${ }^{3}$ \\ Zhu-qing Zhong ${ }^{4}$ \\ Qi-feng Yi ${ }^{4}$ \\ Sai-nan Zeng ${ }^{4}$ \\ Jun-hua $\mathrm{Hu}^{5}$ \\ Jian-da Zhou ${ }^{6}$
}

Objectives: to investigate the quality of life and the associated factors on left behind elderly in rural China. Method: the research was conducted cluster sampling to select 456 elderly left behind when family members migrated out of rural China to participate in a cross-sectional study by completing a general data questionnaire and Quality of Life questionnaire. Results: $91.5 \%$ of the elderly requested psychological counseling and education. For the elderly, scores for mental health $(39.56 \pm 13.73)$ were significantly lower compared with Chinese standard data $(61.6 \pm 13.7)(P<0.001)$. Age, chronic disease type, gender, residence pattern and economic support from children were the main psychological factors influencing this population. Conclusion: mental health is the most important factor influencing quality of life of elderly left behind when family members migrated out of rural China. Our study suggested a need to widely establish a general practitioner team for psychological intervention for improving rural elderly people's Quality of Life level, especially in the psychological domain.

Descriptors: Quality of Life; Rural Health; Aged; Mental Health.

\footnotetext{
${ }^{1}$ Supported by Project of the National Natural Science Foundation of Hunan Provice process \# 13Jj5015 and by Chia Family Foundation Health Fellowship Program which funded by the Yale-China Association (2013-2015).

2 MSc, RN, Third Xiangya Hospital, Central South University, Changsha, Hunan, China.

${ }^{3}$ Specialist in Nursing Management, Professor, Third Xiangya Hospital, Central South University, Changsha, Hunan, China.

${ }^{4}$ MSc, Associate Professor, Third Xiangya Hospital, Central South University, Changsha, Hunan, China.

${ }^{5} \mathrm{PhD}$, Professor, Business School, Central South University, Changsha, Hunan, China.

${ }^{6} \mathrm{PhD}$, Professor, Science Department, Third Xiangya Hospital, Central South University, Changsha, Hunan, China. Professor, Business School, Central South University, Changsha, Hunan, China.
}

Corresponding Author:

Jianda Zhou

Third Xiangya Hospital. Central South University

138 Tongzipo Road

Changsha

410013, Hunan, China

E-mail: doctorzhoujianda@163.com
Copyright (c) 2014 Revista Latino-Americana de Enfermagem This is an Open Access article distributed under the terms of the Creative Commons Attribution Non-Commercial License (CC BY-NC).

This license lets others distribute, remix, tweak, and build upon your work non-commercially, and although their new works must also acknowledge you and be non-commercial, they don't have to license their derivative works on the same terms. 


\section{Introduction}

Migration within developing countries is often temporary, circular, and/or flexible, with only some household members participating, which results in divided households and family members being left behind(1). Elderly who are left behind when family members migrated out of rural areas are a severe social problem in China. Based on the Farmer Workers Report in 2009, formulated by the National Bureau of Statistics of China, over 1,450,000 Chinese farmers migrated to cities to seek work ${ }^{(2)}$, with their parents staying at home. Numerous elderly live in the country and are often termed "left behind elderly"(3). Studies suggest that there were about 18 million left behind elderly in China ten years ago(4-5). In October 2011, the Gerontology Society of China reported that there were 40 millions rural left behind elderly, comprising $37 \%$ of all rural elderly(4). These individuals often feel lonely because they are not being cared for by the younger generation. In addition, many left behind elderly suffer from multiple chronic diseases and are severely indisposed(5). Because of incomplete residence registries, lack of social security, and inadequate housing for the fluid population in China, the number of Chinese left behind elderly continues to increase ${ }^{(6-7)}$. It has been revealed that those left behind experience various emotions, ranging from emotional ambivalence to anger and distress ${ }^{(8)}$. The left behind elderly, who often lack care, have become a significant problem in society, especially in regard to public health management. Their physiological and psychological health, in particular their psychological status, has been a key issue for community care in China.

The term quality of life (QOL) references the general well-being of individuals and societies. The term is used in a wide range of contexts, including the fields of international development, healthcare, and politics. Standard indicators of quality of life include not only wealth and employment but also the constructed environment, physical and mental health, education, recreation and leisure time, and social belonging. This study investigated the main factors affecting QOL of rural left behind elderly by analyzing their general data and residence data. The study also evaluated their QOL by sampling, proposing strategies to improve $\mathrm{QOL}$, and provided objective quantitative evidence for principles and policies that can be developed by relevant agencies.

\section{Methods}

\section{Participants}

In August 2011, 456 left behind elderly over 60 years of age from seven villages of Duoshan Town, Lengshuijiang City, Hunan Province participated in this investigation. All subjects provided informed consent in writing. Exclusion criteria included being affected by blurred vision despite wearing presbyopic glasses, and having mental disorders. The local government assisted with the investigation. All subjects were given 20 Chinese yuan and a sanitation manual as gifts. Informed consent was obtained from each subject and this work was approved by the Ethics Committee of the Third Xiangya Hospital of Central South University.

\section{Measures}

Tools

General data questionnaire: Information on gender, age, educational level, residence type, medical insurance, types of chronic diseases, economic support, frequency of children's visits, history of psychological counseling and psychological education were included.

QOL questionnaire (WHOQOL-BREF-Chinese Version $\left.{ }^{(9)}\right)$ : There were 26 items containing two objective items (overall QOL and general health status) and 24 other items divided into four domains: physiological (seven items), psychological (six items), social relationships (three items) and environment (eight items). Overall QOL and general health status were separately scored (1-5 points). The score for each domain was equal to the mean score for all items $\times 4$. Therefore, the score for each domain ranged from 4 to 20 points. A high score represented high $\mathrm{QOL}$ in that domain. The score for each domain was converted into a centesimal grade: the score after conversion was equal to (original score -4 ) $(100 / 16)^{(10)}$. The WHOQOL has exhibited good construct validity, content validity, retest coefficients and sensitivity in different installations and populations ${ }^{(10-11)}$.

\section{Procedure}

The study team was comprised of one chief nurse, one associate chief nurse, 16 nursing postgraduates and one investigation secretary. First, team members guided subjects in signing informed consent forms and explained the study purpose, as well as what psychological counseling and education meant. All questionnaires were completed anonymously. To increase accuracy of the questionnaires, the time allowed for responding 
was 30-45 minutes. We provided presbyopic glasses, and an assistant loudly read titles and options. Twenty assistants were all nurses who worked in the local community clinics, and accepted two days of training for the investigation plan and questionnaire items. Subjects then completed the questionnaires by themselves.

Data analysis

All information from the questionnaires was entered into a computer according to serial numbers. Both descriptive and inferential statistics were used for data analysis using SPSS 17.0 software. A value of $p<0.05$ was considered statistically significant. An predefined alpha of 0.05 was determined.

\section{Results}

\section{General conditions}

A total of 456 questionnaires were distributed, and 434 valid questionnaires (95.18\%) were returned. General conditions of the subjects are shown in Table 1 . They included less than a primary school education (93.3\%), at least two chronic diseases (61.1\%), low economic support (65.2\%), and living alone (38.0\%). Moreover, $92.4 \%$ of the left behind elderly did not have history of psychological counseling or education, and $91.5 \%$ expressed a desire for both.

Table 1 - Characteristics of the participants $(N=434)$

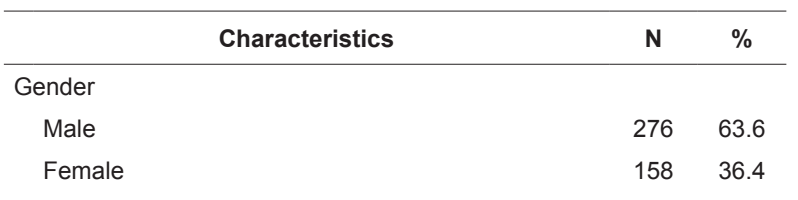

(continue...)
Table 1 - (continuation)

\begin{tabular}{|c|c|c|}
\hline Characteristics & $\mathbf{N}$ & $\%$ \\
\hline \multicolumn{3}{|l|}{ Age (year) } \\
\hline $60-69$ & 187 & 43.1 \\
\hline $70-79$ & 189 & 43.5 \\
\hline$\geq 80$ & 58 & 13.4 \\
\hline \multicolumn{3}{|l|}{ Education } \\
\hline Less than a primary school education & 405 & 93.3 \\
\hline Primary school & 21 & 4.8 \\
\hline Junior high school and above & 8 & 1.8 \\
\hline \multicolumn{3}{|l|}{ Type of residence } \\
\hline Living alone & 165 & 38.0 \\
\hline Living with spouse & 78 & 18.0 \\
\hline Living with other family members & 191 & 44.0 \\
\hline \multicolumn{3}{|l|}{ Insurance } \\
\hline No medical insurance & 23 & 5.3 \\
\hline New rural cooperative medical system (NCMS) & 392 & 90.3 \\
\hline Other medical insurance & 19 & 4.4 \\
\hline \multicolumn{3}{|l|}{ Number of chronic diseases } \\
\hline 0 & 25 & 5.8 \\
\hline 1 & 144 & 33.2 \\
\hline$\geq 2$ & 265 & 61.1 \\
\hline \multicolumn{3}{|l|}{ Economic support } \\
\hline Low & 283 & 65.2 \\
\hline Middle & 129 & 29.7 \\
\hline High & 22 & 5.1 \\
\hline \multicolumn{3}{|l|}{ Visit frequency } \\
\hline 1 month & 21 & 4.8 \\
\hline$<6$ months & 76 & 17.5 \\
\hline$\geq 6$ months & 337 & 77.6 \\
\hline \multicolumn{3}{|l|}{$\begin{array}{l}\text { History of psychological counseling and psychological } \\
\text { education }\end{array}$} \\
\hline Yes & 33 & 7.6 \\
\hline No & 401 & 92.4 \\
\hline \multicolumn{3}{|l|}{$\begin{array}{l}\text { Needs of psychological counseling and psychological } \\
\text { education }\end{array}$} \\
\hline Yes & 397 & 91.5 \\
\hline No & 37 & 8.53 \\
\hline
\end{tabular}

Table 2 - Scores for four domains of QOL (means \pm SD) for the left behind elderly compared to Chinese standard data $(N=434)$

\begin{tabular}{lccc}
\hline \multicolumn{1}{c}{ Groups } & $\begin{array}{c}\text { Physiological } \\
\text { domain }\end{array}$ & $\begin{array}{c}\text { Psychological } \\
\text { domain }\end{array}$ & $\begin{array}{c}\text { Social } \\
\text { domain }\end{array}$ \\
\hline Left behind elderly in rural China & $50.23 \pm 12.31$ & $39.56 \pm 13.73$ & $37.23 \pm 9.32$ \\
Chinese standard data & $61.3 \pm 16.3$ & $61.6 \pm 13.7$ & $64.6 \pm 14.2$ \\
$t$ value & -18.741 & -33.439 & -61.151 \\
$p$ value & 0.000 & 0.000 & -21.930 \\
\hline
\end{tabular}

Table 3 - Association between gender and QOL in the left behind elderly $(N=434)$

\begin{tabular}{|c|c|c|c|c|}
\hline Variable & Gender & Mean $\pm S D$ & $t$ value & $p$ value \\
\hline \multirow[t]{2}{*}{ Q1: The subjective attitudes of QOL } & Male & $2.75 \pm 0.43$ & 8.153 & 0.000 \\
\hline & Female & $2.15 \pm 0.87$ & & \\
\hline
\end{tabular}


Table 3 - (continuation)

\begin{tabular}{|c|c|c|c|c|}
\hline Variable & Gender & Mean $\pm S D$ & $t$ value & $p$ value \\
\hline \multirow[t]{2}{*}{ Q2: The subjective attitudes of health condition } & Male & $2.76 \pm 0.43$ & 7.933 & 0.000 \\
\hline & Female & $2.22 \pm 0.81$ & & \\
\hline \multirow[t]{2}{*}{ Physiological domain scores } & Male & $12.78 \pm 1.64$ & 12.038 & 0.000 \\
\hline & Female & $10.73 \pm 1.82$ & & \\
\hline \multirow[t]{2}{*}{ Psychological domain scores } & Male & $9.92 \pm 1.91$ & -4.939 & 0.000 \\
\hline & Female & $11.04 \pm 2.48$ & & \\
\hline \multirow[t]{2}{*}{ Social domain scores } & Male & $12.23 \pm 1.78$ & 2.817 & 0.005 \\
\hline & Female & $11.67 \pm 2.13$ & & \\
\hline \multirow[t]{2}{*}{ Environmental domain scores } & Male & $9.89 \pm 1.27$ & 2.364 & 0.017 \\
\hline & Female & $10.06 \pm 1.82$ & & \\
\hline
\end{tabular}

Table 4 - Association with QOL and type of residence and frequency of children's visits in the left behind elderly $(\mathrm{N}=434)$

\begin{tabular}{|c|c|c|c|c|c|c|c|c|}
\hline Variable & Residence & $\mathbf{N}$ & Mean rank & $\mathrm{H}$ value & $\begin{array}{c}\text { Visit } \\
\text { frequency }\end{array}$ & $\mathbf{N}$ & Mean rank & $\mathrm{H}$ value \\
\hline \multirow[t]{3}{*}{ Physiological } & Living alone & 165 & 241.51 & $26.038^{*}$ & 1 month & 21 & 217.48 & 1.699 \\
\hline & Living with spouse & 78 & 155.44 & & $<6$ months & 76 & 200.77 & \\
\hline & Living with other family members & 191 & 222.10 & & $\geq 6$ months & 337 & 221.27 & \\
\hline \multirow[t]{3}{*}{ Psychological } & Living alone & 165 & 175.27 & $105.738^{*}$ & 1 month & 21 & 224.50 & $42.153^{\dagger}$ \\
\hline & Living with spouse & 78 & 345.69 & & $<6$ months & 76 & 300.45 & \\
\hline & Living with other family members & 191 & 201.63 & & $\geq 6$ months & 337 & 198.36 & \\
\hline \multirow[t]{3}{*}{ Social } & Living alone & 165 & 199.29 & $35.375^{*}$ & 1 month & 21 & 209.69 & .708 \\
\hline & Living with spouse & 78 & 290.63 & & $<6$ months & 76 & 227.65 & \\
\hline & Living with other family members & 191 & 203.36 & & $\geq 6$ months & 337 & 215.70 & \\
\hline \multirow[t]{3}{*}{ Environment } & Living alone & 165 & 224.54 & 1.552 & 1 month & 21 & 182.45 & $14.628^{\dagger}$ \\
\hline & Living with spouse & 78 & 203.26 & & $<6$ months & 76 & 265.53 & \\
\hline & Living with other family members & 191 & 217.24 & & $\geq 6$ months & 337 & 208.85 & \\
\hline
\end{tabular}

*Living: $p<0.05$

+Visit: $p<0.05$

\section{Global assessment of QOL of the left behind elderly}

$\mathrm{QOL}$ of the left behind elderly was significantly lower compared with Chinese standard data(12) $(P<0.001)$. Mean scores for physiological, psychological, social relationships and environment domains in this population were $(50.23 \pm 12.31),(39.56 \pm 13.73),(37.23 \pm 9.32)$ and (50.19 12.08$)$, respectively, representing significant differences compared with Chinese standard data $(p<0.001$; Table 2). Of the seven items in the physiological domain, movement and sleep were ranked lowest. Of the six items in the psychological domain, positive affection and mental status were ranked lowest. Of the three items in the social relationships domain, sexual activity was the lowest ranked. In the environment domain, safety and economy were ranked lowest. Pearson correlation analysis revealed a significant correlation of scores for the all four domains $(P<0.001)$.

\section{Comparison of QOL of rural left behind elderly of different genders}

As displayed in Table 3, the domains in which gender greatly affected QOL were physiological, psychological, social relationships and environment. Scores for the psychological and environment domains were significantly higher for females than for males. However, scores for the physiological and social relationships domains were significantly higher for males than for females. Subjective evaluations of QOL and health status were noticeably higher in males than in females.

Comparison of QOL of the left behind elderly by residence type and frequency of children's visits, as well as history of psychological counseling and education

Significant differences in scores for physiological, psychological and social relationships domains were found in the left behind elderly living alone compared 
with those with other residence types $(P<0.05)$. However, no significant difference was detected in the environment domain ( $P>0.05$; Table 4).

Significant differences in psychological and environment domains were found in the left behind elderly based on frequency of children's visits of at least every six months, compared with visits less frequently than every six months $(P<0.05)$.

A total of $92.4 \%$ of left behind elderly had never participated in psychological counseling or education. Scores for psychological, social relationships and environmental domains were significantly higher in the elderly with a history of psychological counseling and education than in those without such history $(P<0.05)$.

\section{Multiple linear regression equation of the psychological domain of QOL and associated variables}

The linear regression model explained $37.2 \%$ of the variation of the psychological domain of $\mathrm{QOL}(\mathrm{R}=.610$ and $\mathrm{R} 2=.372$ )

The $F$ test revealed that $F=31.401, P=0.000<0.001$. That is, the multiple linear regression equation fitting the data showed statistical significance.

The high absolute value of the standardized regression coefficient indicated a significant effect of corresponding independent variables on $Y$. The effects of eight independent variables on scores for the psychological domain from large to small were as follows: age, having chronic diseases, gender, residence type, economic support, education level, medical insurance and frequency of children's visits.

\section{Discussion}

This study confirmed that scores for physiological, psychological, social relationships and environment domains of QOL were significantly lower in the left behind elderly compared with Chinese standard data $(P<0.05)$. There are several possible explanations for this discrepancy. The first is low income. Many young people in villages look for work elsewhere to increase their income. As a result, some elderly have to care for their grandchildren. Although their children financially support the grandchildren, the money is for education and not for the grandparents; therefore, money for the elderly is very limited ${ }^{(13)}$. The second explanation is heavy workload. The left behind elderly do farm work as well as taking care of their grandchildren ${ }^{(14)}$. It has been(15) demonstrated that housework and farm work of the left behind elderly are increased when their children leave to work. The third explanation is lack of emotional support. Distance prevents the children from showing their appreciation to their parents. Most rural elderly are supported by their children, but they still felt lonely and unhappy ${ }^{(16)}$. The last explanation is insufficient care. With advanced age, the elderly become very weak, physiologic functions decline and prevalence of illness increases. They depend on others more and more. However, it is often inconvenient for children to take care of their parents ${ }^{(17)}$. The risk of having a chronic disease lasting two weeks to six months is higher in left behind elderly than that in non-left behind elderly(18). When they get sick, the elderly often do not have their children to care for them.

In this study, scores for mental health $(39.56 \pm 13.73)$ of the left behind elderly were significantly lower compared with Chinese standard data $(61.6 \pm 13.7)(p<0.001)$. Of the six items in the psychological domain, positive affection and mental status were ranked lowest. Age, residence type, types of chronic diseases, gender and economic support were major factors influencing scores in the psychological domain. In addition, $91.5 \%$ of the left behind elderly requested psychological counseling and education. These findings suggest that mental health is the main factor influencing QOL for the left behind elderly in rural China. Depression and anxiety are common mental problems among this population. The incidence of depressive symptoms in the elderly in the city of Xian was $24.9 \%^{(19)}$. A previous study found that the rural elderly had depressive symptoms, and their anxiety symptoms frequently became depression or a combination of anxiety and depression(20). As urbanization has increased, more young people have migrated away from their family homes, and the situation of elderly people living with their grandchildren has become more common. Separation from or loss of a spouse adversely affects the elders' psychological, physiological and social adjustment, and influences their $\mathrm{QOL}^{(21)}$. Thus, residence type is a main influencing factor related to illnesses lasting two weeks, as well as chronic diseases ${ }^{(14)}$. Neglect of mental health causes a high incidence of body-mind-related diseases in the left behind elderly, especially in villages. Lack of knowledge causes the elderly and their family members to pay attention to physical health but neglect mental health. Thus, mental problems are often not treated in a timely manner(1). Therefore, the left behind elderly in rural China urgently need psychological help. 
In China, with the transfer of surplus rural workers, the proportion of rural elderly has grown, and the number of left behind elderly will continue to increase, representing an irreversible pattern. At present, strategies and policies related to aging are mainly focused on the elderly living in cities. Close attention is not paid to the rural elderly, in particular the left behind elderly. It is important to improve this population's QOL to lessen the economic burden of the rural family, promote economic development and maintain social harmony. Mental health interventions for the rural left behind elderly are urgently needed. Current rural health services are mainly devoted to physiological and environmental domains, and neglect mental health. The present study indicates that we should pay greater attention to the mental health of these elderly, especially those who live alone. We suggest formulating a standard rural community health service plan, developing community and family resources, and forming a diagnosis and treatment team comprised of experts from medical schools and clinical hospitals who will focus on mental interventions. Moreover, psychologists specializing in geriatrics should be invited to be advisors.

Although this study was conducted with a large sample, there are several limitations. First, findings were based on self-report measures. Self-report data have been criticized for reflecting potential response bias. However, in this study all of the questionnaires were anonymously completed. This strategy can increase the accuracy of the questionnaires and reduce response bias. Second, this study was conducted in only one town in a rural area, which limits the generalizability of the findings. However, the subjects represented different genders, ages, educational levels and residence types, which minimize sampling bias. We recommend verifying the current findings in a study including multiple rural towns or areas. Third, this study included only the left behind elderly who had just entered or were waiting to enter a new rural cooperative medical system. A follow-up study is needed to see whether these elders' QOL improved after being involved in the system. Fourth, the questionnaire reflected subjective investigation. In future research, appropriate modifications should be made to improve the questionnaire. Despite these limitations, the present research provides evidence of widespread poor psychological health among the rural left behind elderly.

\section{Conclusion}

This study suggests that the QOL of the left behind elderly is markedly lower than that of the general population. We argue that the entire society should pay attention to the physiological, psychological, social relationships and environmental domains of $\mathrm{QOL}$, especially focusing on mental health in the left behind elderly in rural China. Age, residence type, types of chronic diseases, gender and economic support are major factors influencing scores for the psychological domain. We should reinforce services for rural areas and public health, which can improve mental health and elevate QOL of the left behind elderly.

\section{References}

1. Whitehead A, Hashim I. Children and migration Background Paper for DFID Migration Team. 2005.

2. National Bureau of Statistics of China. Farmer Workers Report in 2009.[acesso 15 nov 2012]; Disponível em: http://www.stats.gov.cn/was40/gjtjj_detail.jsp?search word $=\%$ C8 $\%$ AB $\%$ B9\%FA\%C5\%A9\%C3\%F1\%B9\%A4 $\%$ D7\%DC\%C1\%BF\&presearchword=\%C5\%A9\%B4\%E $5 \&$ channelid $=6697 \&$ record $=2$

3. He CZ, Ye JZ. Review on the study of rural left behind elderly. J Northeast Agric Univ (Social Sciences Edition). 2009;26:24-34.

4. Xinhua Net. Rural elderly population was more than urban. [acesso 15 nov 2012]; Disponível em: http:// www.ccfc.zju.edu.cn/a/sannongtoushi/2011/1005/ 7661.html

5. Wang LJ. Reseach on quality of life and its influecing factors of the elderly staying in rural areas of Jining. Shandong: Shandong University; 2007.

6. Zhou FL. Study on left behind elders in China. Northwest Population J. 2006;1:46-56

7. He CZ, Ye JZ. Impact Study on the Rural Labor Force Migrant Working to the Life Care of Left behind Elders. Problems Agric Econ.2010;3:46-53.

8. Marchetti-Mercer MC. Those easily forgotten: the impact of emigration on those left behind. Fam Process. 2012;51:376-90.

9. Zhang Y, Qu B, Lun S, Wang D, Guo Y, Liu J. Quality of life of medical students in China: a study using the WHOQOL-BREF. PLoS One. 2012;7(11):e49714.

10. Neusa SR, Mick JP, Donald MB, Marcelo PF. The EUROHIS-QOL 8-Item Index: Comparative Psychometric Properties to Its Parent WHOQOL-BREF. Value in Health. 2012;15:449-57. 
11. Chien CW, Wang JD, Yao G, Hsue IP, Hsieh CL. Agreement Between the WHOQOL-BREF Chinese and Taiwanese Versions in the Elderly. J Formos Med Assoc. 2009;108:164-9.

12. Featured Products \& Services [Internet]. Michigan: China Data Center, Michigan University. [acesso 15 nov 2012]. Disponível em: http://www.chinadatacenter.org/ Data/Services.aspx

13. Guo Y. Analysis on social support in left behind elderly in five provinces -Anhui, Henan, Hunan, Jiangxi and Sichuan. Forward Position. 2011;287:136-8.

14. Luo M, Jiang Q, Zhang JY, Tan L, Ying GY, Gan HP. Research factors affected to the health condition of left behind elderly in rural areas. J Sichuan Univ. (Med Sci Edi). 2011;42:409-12.

15. Du P, Ding ZH, Li QM. The influence of rural children moved to the cities in searching of jobs on left behind elderly. Pop Res.2004;28:44-52.

16. Paul M, Shane D. Older people and poverty in rural Britain: Material hardships, cultural denials and social inclusions. J Rural Stud. 2012;28:389-97.

17. Hu QQ. Study on care patterns for rural left behind elderly in Chinese urbanization. J Nanjing Coll Pop Program Manage. 2006;22:25-8.

18. Cai M. Study on the survival conditions of rural left behind elderly under Chinese "labor economy". Rural Econ. 2006;4:118-21.

19. Fan SH, Hua QZ, Ma Y, Yu Y, Zhang MX, Nan J, Wang $X N$, Zhao YL.A Study on incidence and riskfactors of depression among aged people in community of Xian city. Chinese Nurs Res. 2007;21:483-4.

20. Nie M, Wang QH, Yao YS. Advances in study of psychological problems of left behind and empty-nest elders. Chinese J Gerontol. 2011;31:2364-6.

21. Yuan Q, He GP, Feng $H$, Gao J. Analysis of influencing factors on depressive state of the aged in the community in Changsha City. Chinese J Gerontol. 2010;30:746-8. 